\title{
Correction to: Will Brexit Damage our Security and Defence?
}

\section{Correction to:}

S. Duke, Will Brexit Damage our Security and Defence? https://doi.org/10.1007/978-3-319-96107-1

The book was inadvertently published with incorrect Figure 1.1 and 2.1. The figures have been updated in the book.

The updated online version of the book can be found at https://doi.org/10.1007/978-3-319-96107-1 